\title{
COMUNICAÇÃO
}

\section{ESTUDO DOS MÉTODOS DE EXTRAÇÃO DE CAROTENÓIDES EM CENOURA POR FLUIDO SUPERCRÍTICO (EFS) E CONVENCIONAL}

\author{
A study of the methods of carotenoid extraction in carrots using supercritical fluid extraction \\ (sfe) and conventional methods
}

\author{
Ellem Waleska Nascimento da Fonseca Contado ${ }^{1}$, Leonardo da Silva Patto ${ }^{2}$, Denise Alvarenga Rocha ${ }^{3}$, \\ Celeste Maria Patto de Abreu ${ }^{3}$, Angelita Duarte Corrêa ${ }^{3}$, Custódio Donizete dos Santos ${ }^{3}$
}

\begin{abstract}
RESUMO
A cenoura (Daucus carota L.), planta da família das umbelíferas, produz uma raiz aromática e comestível, sendo uma das hortaliças mais cultivadas no Brasil. Representa a principal fonte de origem vegetal em carotenóides pró-vitamínicos A, especialmente o $\alpha$ e o $\beta$-caroteno, sendo, também, uma grande fonte de fibra dietética, antioxidantes e minerais. Conduziu-se este trabalho, com o objetivo de avaliar dois processos de extração de $\beta$-caroteno, fluído super crítico (EFS) e o convencional e analisar a composição centesimal da cenoura in natura. O teor de $\beta$-caroteno obtido pela extração por EFS e por convencional foi de $2.457 \mathrm{e} 2.455 \mu \mathrm{g} / 100 \mathrm{~g}$, respectivamente. Os valores médios encontrados para a matéria-seca da cenoura foram de: matéria-seca $=8,9 \%$; extrato etéreo $=$ $0,29 \%$; cinzas $=8,11 \%$; fibra bruta $=14,57 \%$, proteína bruta $=6,4 \%$, extrato não nitrogenado $=6,3 \%$ e valor calórico $=27,7 \mathrm{kcal}$. Conclui-se que a extração de carotenóides em cenoura pelo fluido supercritico é uma técnica de separação viável, pois este fluido é inerte, não deixa resíduo final e não gera resíduo ambiental. Pelos teores encontrados conclui-se também que as cenouras são boas fontes de fibras, apresentam alto teor de umidade e baixo teor de gorduras, cinzas e valor calórico.
\end{abstract}

Termos para indexação: Cenoura, extração, fluido supercrítico, $\beta$-caroteno.

\begin{abstract}
The carrot (Daucus carota L.) is a plant of the Umbelliferae family. It produces an aromatic and edible root, and is one of the most widely cultivated vegetable in Brazil. It represents the main source of plant-origin, pro-vitamin A carotenoids, especially $\alpha$ and $\beta$-carotene, and is also a great source of dietary fiber, antioxidants and minerals. This study aimed to evaluate two methods of extraction of $\beta$-carotene, supercritical fluid (SFE) and conventional, and to examine the proximate composition of the carrot in nature. The contents of $\beta$-carotene obtained by SFE and by conventional extraction were 2,457 and $2,455 \mu \mathrm{g} / 100 \mathrm{~g}$, respectively. The average values found for the dry-matter of the carrot were: dry matter $=8.9 \%$; ether extract $=0.29 \%$; ashes $=8.11 \%$, crude fiber $=14.57 \%$, crude protein $=6,4 \%$, non- nitrogen extract $=6.3 \%$ and caloric value $=27.7 \mathrm{kcal}$. It is concluded that the extraction of carotenoids using the supercritical fluid is a viable separation technique since this fluid is inert and does not generate waste or final environmental waste. It can be concluded from the levels found that carrots are good sources of fiber, present high moisture content and low fat, ash and calorific value.
\end{abstract}

Index terms: Carrot, extraction, supercritical fluid, $\beta$-carotene.

(Recebido em 22 de abril de 2008 e aprovado em 2 de setembro de 2009)

Os carotenóides têm sido objeto de inúmeros estudos, em razão das suas importantes funções biológicas no ser humano, além de seu papel como pigmentos naturais. Esses estudos datam de 1831, quando isolou-se o pigmento de cenoura para o qual se deu o nome de caroteno (carrot root). Somente em 1919, descobriu-se que existia uma relação entre os carotenóides e a vitamina A e, em 1930, estabeleceu-se que alguns deles possuem atividade provitamínica A. Tais como: $(\beta$-caroteno, $\alpha$-caroteno e $\beta$ zeacaroteno), podendo se transformar em vitamina A no organismo animal (Rodriguez-Amaya, 1993). Em virtude da diversidade de funções e ações que são atribuídas aos carotenóides, seu estudo reúne pesquisadores das mais variadas áreas como química, agronômica e saúde (Rodriguez-Amaya, 1993).

Carotenóides são compostos extremamente suceptíveis às reações oxidativas, em razão alto grau de insaturação das ligações. Nas frutas e vegetais in natura, a estrutura celular e a complexação com proteína lhe conferem uma certa estabilidade. Durante as várias etapas

1Universidade Federal de Lavras/UFLA - Departamento de Química/DEX - C.x. P. 3037 - 37200-000 - Lavras, MG - ellem.waleska@ig.com.br ${ }^{2}$ Universidade Federal de Lavras/UFLA - Departamento de Agricultura/DAG - Lavras, MG

${ }^{3}$ Universidade Federal de Lavras/UFLA - Departamento de Química/DEX - Lavras, MG 
do processamento de extração, essa ultraestrutura e os complexos podem ser quebrados, expondo os carotenóides a fatores adversos, levando à sua destruição. A estabilidade varia largamente no processamento e na estocagem, dependendo da temperatura, disponibilidade de oxigênio, exposição à luz, atividade de agua, acidez, presença de metais e da própria estrutura (Chiclester \& Mcfeeters, 1971; Godoy \& Rodriguez-Amaya, 1987; Pádua \& Rodriguez-Amaya, 1987). A presença de agentes antioxidantes naturais, como ácido ascórbico e tocoferol, retardam a oxidação (Bauernfeind, 1981).

Os benefícios que a pró-vitamina A proporciona ao organismo vão desde fortalecimento do sistema imunológico até ações benéficas contra doenças degenerativas, como o câncer, doenças cardiovasculares, degeneração macular e formação de cataratas. Especificamente na população infantil, a deficiência dessa vitamina, além de aumentar o risco de contrair as doenças mencionadas, também prejudica o desenvolvimento da criança na escola, por retardar o seu desenvolvimento físico e intelectual (raquitismo e retardamento, respectivamente), contribuindo para uma má formação educacional e, consequentemente, a reprovação escolar e, por último, o abandono escolar. Se um país tomasse medidas adequadas para erradicar a deficiência de vitamina $\mathrm{A}$, teria rapidamente como benefícios uma população mais sadia, com uma maior produtividade, com um nível educacional mais elevado, além de diminuir os gastos com medicamentos, atendimento hospitalar e apoio financeiro (aposentadoria) a pessoas afastadas prematuramente dos seus empregos. Outra vantagem dos carotenóides é que eles podem ser consumidos em doses consideravelmente elevedas, sem ocorrer acúmulo prejudicial ao organismo.

O estado supercrítico foi descrito pela primeira vez em 1822, pelo Barão Gagniard de la Tour. Em 1879, Hannay e Hogarth demonstraram o poder solvente dos fluidos supercríticos. Porém, as primeiras aplicações industriais e analíticas somente ocorreram na década de 1970 (Sihvonen et al., 1999). A primeira planta industrial de extração com $\mathrm{CO}_{2}$-SC foi instalada em 1978, para descafeinização de grão verdes de café (Kaffe HAG AG - Alemanha). Dois anos mais tarde, surge outra indústria (Carlton \& Breweries Austrália), para a extração de flavour de lúpulo (Raventós et al., 2002).

O estado supercrítico é alcançado quando a temperatura e a pressão de uma substância pura são aumentadas acima do seu ponto crítico (Figura 1). A temperatura crítica é definida como a temperatura máxima, na qual um gás pode ser convertido em um líquido, pelo aumento de pressão. Da mesma forma, a pressão crítica é a pressão máxima, na qual um líquido pode ser convertido em um gás, mediante o aumento da temperatura (Leitner, 2000).

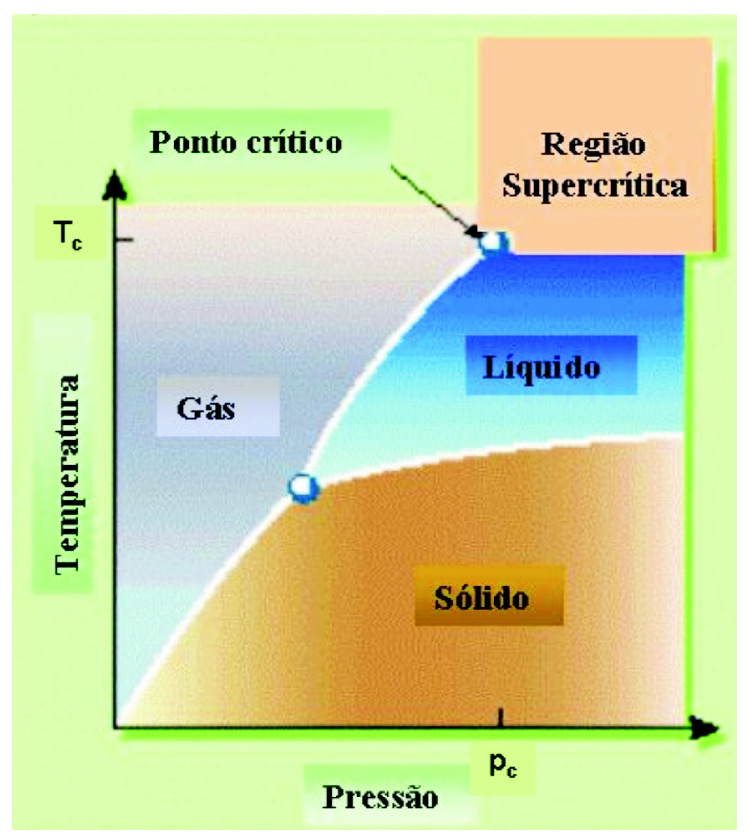

Figura 1 - Diagrama de fases para uma substância pura $\left(\mathrm{T}_{\mathrm{c}}=\right.$ temperatura crítica e $\mathrm{p}_{\mathrm{c}}=$ pressão crítica $)$. Fonte: Poliakoff \& King (2001). 
No estado supercrítico, desaparece a distinção entre as fases líquida e gasosa e o fluido não pode mais ser liquefeito pelo aumento de pressão e nem pode tornar-se gasoso, pelo aumento de temperatura. Assim, propriedades físico-químicas, tais como densidade, difusividade, constante dielétrica e viscosidade podem ser facilmente controladas pelas alterações de pressão e/ou temperatura, sem cruzar os limites de fases (Del Valle \& Aguilera, 1999).

Fluidos supercríticos (FSC) apresentam meios bastante atrativos para o processamento de produtos de ocorrência natural, decorrente das várias características distintas, tais como, facilidade de recuperação do soluto e reciclagem do solvente, com a simples manipulação de temperatura e/ou pressão; a possibilidade de direcionar a separação pela escolha a priori das condições termodinâmicas de temperatura e/ou pressão e, com isso, a sintonia do poder de solvência do fluído usado na extração para uma determinada extração e/ou separação e o controle da seletividade do processo pela escolha apropriada do solvente e da combinação solvente/cosolvente utilizados (Mohamed, 1997).

Esse método também tem sido empregado nas extrações de plantas medicinais, em razão da instabilidade térmica dos princípios ativos e também ao elevado grau de pureza com que esses são obtidos. Para a referida extração, o $\mathrm{CO}_{2}$ é primeiramente liquefeito por compressão a $31^{\circ} \mathrm{C}$. Nessa temperatura, o $\mathrm{CO}_{2}$ atinge um quarto estado, no qual sua viscosidade é analoga à de um gás, mas sua capacidade de dissolução é elevada como à de um líquido. Uma vez efetuada a extração, faz-se o $\mathrm{CO}_{2}$ retornar ao estado gasoso, resultando na sua total eliminação. Uma desvantagem do uso de $\mathrm{CO}_{2}$ supercrítico é a sua baixa polaridade, fazendo a extração de compostos polares mais difíceis. Contudo, com o uso de cossolventes adequados, pode-se elevar a seletividade e solubilidade do $\mathrm{CO}_{2}$ supercrítico em solutos polares, como, por exemplo, a adição de etanol, metanol ou água em baixas temperaturas (Fajardo, 1997; Li \& Hartland, 2002).

A extração por Fluidos Supercríticos (FSC) apresenta vários atrativos para o processamento de produtos de ocorrência natural de fácil oxidação, decorrente das várias características distintas, tais como a facilidade de recuperação do soluto e reciclagem do solvente com a simples manipulação de temperatura e/ou pressão, a possibilidade de direcionar a separação pela escolha a priori das condições termodinâmicas de temperatura e/ou a pressão e, com isso, a sintonia do poder de solvência do fluido usado na extração para uma determinada extração e/ ou separação, e o controle da seletividade do processo pela escolha apropriada do solvente e da combinação solvente /cossolvente utilizados. Fluidos inertes não tóxicos, não inflamáveis, não agressivos ao meio ambiente e com temperaturas críticas baixas, como dióxido de carbono, apresentam, além disso, a possibilidade da realização da extração e do fracionamento sem os riscos de deixar resíduos indesejáveis e/ou degradar termicamente os produtos obtidos, o que ocorre quando se extrai carotenóides pelo método convencional. Por isso, a tecnologia de FSC é uma alternativa viável de extração, principalmente usando dióxido de carbono como extrator.

Neste trabalho, objetivou-se a extração de carotenóides presentes na cenoura pelo uso do fluído supercrítico $\left(\mathrm{CO}_{2}\right)$ e comparar com um método colorimétrico convencional, por espectofotometria.

O experimento foi realizado no Departamento de Química da Universidade Federal de Lavras, nos Laboratório de Bioquímica e no Centro de Análises e Prospecção Química.

Foram utilizadas cenouras cultivar Nantes obtidas no comércio de Lavras. Coletou-se cerca de 10 quilos de cenoura em três pontos do comércio. As cenouras foram lavadas em água corrente para retirada das impurezas, em seguida mergulhadas em solução de hipoclorito de sódio $1 \%$ por 10 minutos e, novamente, lavadas em água corrente por 3 vezes. A amostra foi triturada, liofilizada, homogenizada. Porções de 100 gramas foram armazenadas em frascos recobertos externamente com papel alumínio para evitar o contato com a luz, em temperatura ambiente até a extração dos carotenóides.

Também foram realizados análises físico-químicas da cenoura in natura e liofilizada.

As análises físicos-químicas foram realizadas conforme descritas abaixo:

- Umidade: método gravimétrico Association of the Agricultural Chemists (Association Official Agricultural Chemists - AOAC, 1990), com secagem a $60^{\circ} \mathrm{C}$, até obter peso constante.

- Extrato etéreo: análise em aparelho tipo de Soxhlet (AOAC, 1990), extração com éter etílico.

- Cinzas: método gravimétrico (AOAC, 1990).

- Proteína total: (AOAC, 1990), o teor de N obtido foi convertido em proteínas totais, multiplicando-se pelo fator de conversão 6,25 .

- Fibra bruta: método gravimétrico (Kamer \& Ginkel, 1952).

- Carboidratos totais: AOAC (1990).

- Valor calórico: Atwater, Osborne \& Voogt (1978).

- Açúcares totais, redutores e não redutores: Somogy, adaptado por Nelson (1994). 
O método utilizado foi Rodriguez-Amaya et al. (1976). Todo o procedimento foi realizado em um ambiente com pouca luminosidade, pois os carotenóides podem degradar-se em presença de luz e calor, e para protegê-los os recipientes utilizados foram recobertos com papel alumínio. A acetona para extração foi resfriada para evitar problemas de vazamento e explosão no liquidificador.

Cinco gramas da cenoura liofilizada, foram liquidificadas com $30 \mathrm{~mL}$ de acetona resfriada, Triturou-a, adicionou 1 a 2 colheres de hiflosupercel, para ajudar na etapa de filtração. Filtrou-se num funil de Buchner, repetindo as operações de trituração e filtração até o desaparecimento completo da cor.

O pigmento extraído foi transferido para um funil de separação com $100 \mathrm{~mL}$ de éter de petróleo. Os pigmentos foram adicionados ao funil em pequenas porções, lavando com um pouco de água destilada, para retirar a acetona, por meio da separação em duas fases, uma superior de éter de petróleo com os carotenóides, e uma inferior de água mais acetona. Descartou a camada inferior e continuou a lavagem até terminar de passar toda a solução de carotenóides. Quando todo o pigmento ficou contido no éter lavou-se a solução mais 4 vezes com água destilada, para que toda a acetona fosse retirada. Recolheu a solução de carotenóides num frasco com tampa.

Adicionou-se uma solução de $10 \mathrm{~mL} \mathrm{KOH} \mathrm{10 \%} \mathrm{em}$ metanol, num volume igual ao obtido na solução de carotenóides, e deixou-se saponificando por 12 horas no escuro a temperatura ambiente.

Lavou-se a solução de pigmentos com água destilada, para remover o álcali, usando um funil de separação e o mesmo procedimento de lavagem do item A.

Recolheu-se a solução de carotenóides (camada superior) num erlemeyer e adicionou-se uma pequena porção de sulfato de sódio anidro, para eliminar a água remanescente, deixando a solução no refrigerador por mais 3 horas.

A solução de carotenóides foi concentrada num evaporador rotatório a vácuo até aproximadamente $10 \mathrm{ml}$.

Uma coluna de vidro empacotada com $\mathrm{MgO}$ : hiflosupercel (1:2) foi montada. Colocou-se uma pequena quantidade de sulfato sodio de anidro no topo. Adicionouse éter de petróleo para umedecer a coluna. Ela foi sempre mantida umedecida com o solvente, para evitar rachaduras, prejudicando a separação cromatográfica.

Eluiu-se a amostra com $50 \mathrm{~mL}$ por vez dos seguintes solventes: éter etílico $2 \%$, éter etílico $4 \%$, éter etílico $8 \%$, acetona $2 \%$, acetona $4 \%$, acetona $8 \%$ e acetona $10 \%$, todos dissovidos em éter de petróleo. As frações de cada solvente foram recolhidas separadamente em erlenmeyer com tampa.
O volume final de cada fração de carotenóides foi completado para $25 \mathrm{~mL}$ em balão volumétrico com éter de petróleo. Foi lida cada fração num espectrofotômetro de duplo feixe com registrador. É característica dos carotenóides apresentar três máximos no seu espectro de absorção na região visível $(350 \mathrm{~nm}$ a $550 \mathrm{~nm})$.

Para identificação, comparou-se os três máximos do espectro com valores previamente tabelados por Davies (1976), usando éter de petróleo como solvente. Para quantificação, mediu-se a absorbância do pico maior (o do meio) e aplicou-se a Lei de Beer, utilizando-se a seguinte fórmula:

Carotenóides $(\mathrm{ug})=\frac{\text { volume }(\mathrm{mL}) \cdot \text { absorvância máxima } \cdot 10^{6}}{\mathrm{E}^{1 \%}{ }_{1 \mathrm{~cm}} \cdot \text { peso da amostra }(\mathrm{g}) \cdot 100}$

Onde:

$\mathrm{E}^{1 \%}{ }_{1 \mathrm{~cm}}=$ absortividade, tabelada para cada carotenóide (Davies, 1976).

$\mathrm{O}$ experimento foi realizado utilizando-se o equipamento SFT - 150 SFE System, da empresa Supercritical Fluid Tecnologies, Inc. Cenoura liofilizada (5 gramas) foi misturada com esferas de vidro de diâmetro médio de $2 \mathrm{~mm}$. Esse material (cenoura liofilizada + esferas de vidro) foi empacotado no extrator manualmente com o auxílio de um bastão de vidro, dentro de sacolas de tecido (composição: $90 \%$ nylon $+10 \%$ elastano). Utilizaram-se esferas de vidro com o objetivo de completar o volume do extrator, fixando a massa de matéria-prima empregada na extração (5 gramas de cenoura liofilizada). Após o empacotamento da coluna, foi feita uma pressurização do sistema apenas com $\mathrm{CO}_{2}$ para retirada do ar da coluna de extração. Em seguida, injetou-se o extrator $\left(\mathrm{CO}_{2}+\right.$ cosolvente etanol) na coluna, nas condições de operação (400bar e $40^{\circ} \mathrm{C}$ ). Utilizou-se um período estático de 30 minutos. O tempo necessário para atingir o equilíbrio prático foi determinado por testes preliminares, $\mathrm{O}$ período de extração dinâmico foi de 3 horas.

Nos experimentos realizados com misturas de $\mathrm{CO}_{2}+$ co-solvente etanol, a massa de cossolvente injetada na coluna durante o período estático foi calculada, considerando a fração molar da mistura de operação (10\% de cossolvente) (Sandler, 1987). Atingido o período estático (30 minutos), abriu-se a válvula situada após a coluna e iniciou-se a extração.

O volume final de cada fração de carotenóides para 10 $\mathrm{mL}$ foi aferido com éter de petróleo. As frações foram lidas num espectrofotômetro de duplo feixe com registrador. Para identificação, compararam-se os três máximos do espectro com valores previamente tabelados em Davies (1976), usando éter de petróleo como branco. Para quantificação, medir a 
absorbância do pico maior (o meio) e aplicar a Lei de Beer, utilizando a seguinte fórmula: (Cecchi, 2003). Carotenóides $(\mathrm{ug})=\frac{\text { volume }(\mathrm{mL}) \cdot \text { absorvância máxima } \cdot 10^{6}}{\mathrm{E}^{1 \%}{ }_{1 \mathrm{~cm}} \cdot \text { peso da } \operatorname{amostra}(\mathrm{g}) \cdot 100}$

Onde:

$\mathrm{E}^{1 \%}{ }_{1 \mathrm{~cm}}=$ absortividade, tabelada para cada carotenóide (Davies, 1976).

Os valores médios obtidos da composição centesimal da cenoura variedade Nantes estão representados na Tabela 1, onde também encontram-se os dados publicados das variedades Brasília (Almeida-Muradian et al., 1997), Beta 3 (Almeida-Muradian et al., 1997) e Baby (USDA, 2001).

Observa-se que os teores de umidade encontrados na variedade Nantes foram semelhantes aos das variedades Brasília, Beta 3 e Baby. Os valores de cinzas e carboidratos foram semelhantes aos da variedade Beta 3 apresentado pela Universidade de São Paulo - USP (2005) e Baby. O teor de extrato etéreo encontrado na variedade Nantes foi próximo o da variedade Beta 3 , embora os demais apresentem valores bem diferenciados entre si. Os teores de proteína e fibra da cultivar Nantes apresentaram uma diferença de aproximadamente cinquenta por cento das cultivares Brasília e Beta 3, já comparando com a cultivar Baby o valor de proteína apresentou-se próximo e o valor de fibra não apresentou uma diferença tão alta com a mesma variedade.

A cultivar Nantes apresentou um valor calórico próximo das cultivares Brasília e Beta 3, mesmo apresentando menor teor de extrato etéreo que as outras cultivares, entretanto apresentou maior porcentagem de carboidratos em relação às outras duas cultivares.
O legume para ser indicado como uma boa fonte de fibra tem que apresentar teores em torno de 1,5\% ou mais, de acordo com os dados apresentados nas tabelas de (Almeida-Muradian et al., 1997). Uma vez que a cenoura é indicada como fonte rica em fibras de baixo valor calórico, a variedade Nantes não é a mais indicada como fonte de fibra, por apresentar valor $(1,3)$ abaixo do recomendado.

Sabe se que a composição centesimal pode ser influenciada por vários fatores tais como: tipo de solo, clima, adubação, estado fisiológico, etc. Isso pode explicar as diferenças de resultados citados e segundo Ketiku \& Oyenuga (1973) e Brillouet et al. (1981) o estádio de maturação de produtos horticulas também é um dos fatores que influenciam decisivamente nas características desses produtos.

Na Tabela 2, estão representados os teores de $\beta$-carotenos de cenoura Nantes, extraídos por fluído super crítico (FSC) e método convencional (C), expressos em $\mu \mathrm{g}$ de $\beta$-caroteno por $100 \mathrm{~g}$ de cenoura, em 10 repetições.

Verifica-se que o teor de $\beta$-carotenóides extraído pelo método convecional foi superior ao extraído por FSC, embora não tenha ocorrido diferença significativa a $5 \%$ de probabilidade entre os dois métodos estudados de $5 \%$. Em trabalho realizado por Heinonea (1990), verificou-se que o conteúdo de carotenóides em cenoura no verão variou de 2600 a $5500 \mu \mathrm{g} / 100 \mathrm{~g}$. Em 69 amostras de cenouras obtidas em supermercados e bancas em beira de estrada, Bushway et al. (1986) encontraram teores de $\beta$-carotenos entre 3606 e $4003 \mu \mathrm{g} / 100 \mathrm{~g}$, valores bem superiores ao encontrado nesse experimento.

Tabela 1 - Valores das médias da composição centesimal de cenoura das variedades Nantes, Brasília e Beta 3. (umidade\%, bu; extrato etéreo, \%, bs; proteína, \%, bs; fibra bruta, $\%$, bs; cinzas, bs; carboidratos totais, \%, bs) e do valor calórico (cal/100g de cenoura).

\begin{tabular}{|c|c|c|c|c|c|c|c|}
\hline Cenoura & $\begin{array}{l}\text { Umidade } \\
(\%) \text { (MI) }\end{array}$ & $\begin{array}{c}\text { Extrato Etéreo } \\
\text { (\%) (MS) }\end{array}$ & $\begin{array}{l}\text { Proteína } \\
\text { (\%) MS }\end{array}$ & $\begin{array}{l}\text { Fibra } \\
\text { (\%) MS }\end{array}$ & $\begin{array}{l}\text { Cinzas } \\
(\%) \mathrm{MS}\end{array}$ & $\begin{array}{c}\text { Carboidrato } \\
(\text { ENN) }(\%) \text { MS }\end{array}$ & $\begin{array}{l}\text { Valor calórico } \\
\text { (Kcal) }\end{array}$ \\
\hline Nantes in natura & 91,1 & 0,17 & 0,57 & 1,30 & 0,72 & 6,3 & 29,01 \\
\hline $\begin{array}{l}\text { Brasília } \\
\text { (Almeida et.al.) }\end{array}$ & 89,4 & 0,32 & 1,26 & 3,09 & 1,2 & 4,73 & 28,10 \\
\hline $\begin{array}{l}\text { Beta } 3 \\
\text { (Almeida et.al.) }\end{array}$ & 90,48 & 0,16 & 1,01 & 2,85 & 1,09 & 4,41 & 24,23 \\
\hline $\begin{array}{l}\text { Beta } 3 \\
\text { (FCF/USP) }\end{array}$ & 91,89 & 0,20 & 1,01 & 2,81 & 0,81 & 6,09 & 31,66 \\
\hline $\begin{array}{l}\text { Baby } \\
\text { (UNIFESP) }\end{array}$ & 90,35 & 0,13 & 0,64 & 1,8 & 0,63 & 8,24 & 38,47 \\
\hline
\end{tabular}


Tabela 2 - Teores médio de $\beta$-caroteno de cenoura extraídos por fluído super crítico e por método convencional, expressos em $\mu \mathrm{g} / 100 \mathrm{~g}$, em 10 repetições.

\begin{tabular}{lc}
\hline Tratamento & Teor de B-caroteno \\
\hline EFS & 2457 \\
C & 2485 \\
\hline
\end{tabular}

A concentração de $\beta$-caroteno na base sólidos insolúveis de cenoura fresca, desidratada e liofilizada 1725, 1494 e $2383 \mu \mathrm{g} / 100 \mathrm{~g}$, respectivamente durante o branqueamento amostra fresca $1736 \mu \mathrm{g} / 100 \mathrm{~g}$ e amostra branqueada $1458 \mu \mathrm{g} / 100 \mathrm{~g}$.

A concentração de $\beta$-caroteno de cenoura da cultivar Nantes na Base úmida, Base seca e Base sólido insolúveis expressos em $\mu \mathrm{g} / \mathrm{g}$, respectivamente, são 40, 507, 1605.

Chichester \& Mcfeeters (1971) relataram que, durante o processo de liofilização a ultraestrutura e os complexos podem ser quebrados, expondo os carotenóides a fatores adversos e, consequentemente, diminuídos o teor de carotenóides no processo de extração, que emprega a liofilização. Isso justifica o teor de carotenóides estar abaixo dos trabalhos relatados na literatura. Park (1987), num trabalho que comparava conteúdo de carotenos de cenoura fresca com cenoura desidratada em estufa a vácuo, microondas e liofilizadas, encontrou valores em torno de $50 \%$ menores para as amostras liofilizadas e desidratadas em microondas. $\mathrm{O}$ autor concluiu que a desidratação, independentemente do método, reduz significamente os carotenos. A comparação foi feita em base seca, e nenhum tratamento de branqueamento, antes das desidratações, foi realizado.

Cenouras cruas apresentaram teor de $3.401 \mathrm{e}$ $4.584 \mu \mathrm{g} / 100 \mathrm{~g}$ para as amostras da CEAGSP e IAC, respectivamente.

Conforme as condições em que foi realizado este experimento, pode-se concluir que:

A extração de carotenóides em cenoura pelo fluido supercritico é uma técnica de separação viável para as indústrias de alimentos e farmacêuticas, pois este fluido é inerte, não deixa resíduo final e não gera resíduo ambiental. Pelos teores encontrados, conclui-se também que: cenouras são boas fontes de fibras, apresentam alto teor de umidade e baixo teor de gorduras, cinzas e valor calórico.

\section{REFERÊNCIAS BIBLIOGRÁFICAS}

ALMEIDA-MURADIAN, L.B.; POPP, V.; FARIAS, M.P. Provitamin A activity of Brazilian carrots: leaves and roots, raw and cooked and their chemical composition.
Ciência e Tecnologia de Alimentos, Campinas, v.17, n.2, p.120-124, 1997.

ASSOCIATION OFOFFICIAL AGRICULTURAL CHEMISTS. Official methods of the Association of the Agricultural Chemists. 15.ed. Washington, 1990. v.2.

BAUERNFEIND, J.C. Carotenoids as colorants y vitamin a precursors. New Andork: Academic, 1981. 13p.

BRILLOUET, J.M.; TRECHE, S.; SEALY, L. Alterations in cell wall constituintes of yams dioscorea dumetorum and $D$. rontuladata with maturation and storage conditions, relation with post harvest hardening of $D$. dumentorum yam tubers. Journal of Food Science, London, v.46, n.6, p.1964-1967, 1981.

BUSHWAY, R.J.; YANG, A.; YAMANI, A.M. Comparasion of alpha-and beta-carotene contento $\mathrm{f}$ supermarket versus roadside stand produce. Journal Food Quality, London, v.9, p.437, 1986.

CECCHI, H.M. Fundamentos teóricos e práticos em analises de alimentos. 2.ed rev. Campinas: Unicamp, 2003. 207p.

CHICHESTER, C.O.; McFEETERS, R. Pigment degeneration during processing and storage. In: HULME, A.C. (Ed.). The biochemistry of fruits and their products. London: Academic, 1971. p.107.

DAVIES, B.H. Carotenoids. GOODWIN, T.W. (Ed.). Chemistry and biochemistry of plant pigments. London: Academic, 1976. p.38.

DEL VALLE, J.M.; AGUILERA, J.M. Na improved equation for predicting the solubility of vetable oils in supercritical $\mathrm{CO}_{2}$. Industry Engineers Chemistry Research, v.27, p.1551, 1998.

FAJARDO, G. Coparative study of the oil na supercritical $\mathrm{CO}_{2}$ extract of Mexican pimento (Pimenta dioica Merrill). Journal Essential Oil Research, Lawrence, v.9, n.2, p.181-185, 1997.

GODOY, H.T.; RODRIGUES-AMAYA, D.B. Changes inindividual carotenoids on processing and storage of mango (Mangifera indica) slices and puree.

International Journal of Food Science Technology, Amsterdam, v.22, p.451, 1987. 
HEINONEA, M.I. Carotenoids and provitamin A activity of carrot (Daucus carotal.) cultivares. Journal of Agriculture and Food Chemistry, Easton, v.38, p.609, 1990.

KAMER, J.H. van de; GINKEL, L. van. Rapid determination of cruser fiber in cereals. Cereal Chemistry, Saint Paul, v.29, n.4, p.239-251, Oct./Dec. 1952.

KETIKU, A.O.; OYENUGA, Y.A. Changes in the carbohydrate constituints of yam tuber (Dioscorea rotundata pois.) during growth. Journal of the Science of food and Agricultural, Washington, v.24, n.4, p.367373, 1973.

LEITNER, W. Desinned to dissolve. Nature, London, v.405, p.129-130, 2000.

LI, S.; HARTLAND, S. Supercritical fluid extraction of ailkylamides from Echinacea angustifolia. Journal of Supercritical Fluids, Ottawa, v.50, n.14, p.3947-3953, 2002.

MOHAMED, R.S. Extração e fracionamento de produtos de ocorrência natural com fluidos supercriticos. Ciência e Tecnologia de Alimentos, Campinas, v.17, n.4, p.344345, dez. 1997.

NELSON, N.A. A photometric adaptation of Somogyi method for the determination of glucose. Journal Biological Chemisstry, Baltimore, v.135, p.135-375, 1944.

OSBORNE, D.R.; VOOGT, P. The analysis of nutrient in foods. London: Academic, 1978. 158p.

PARK, Y.W. Effect of freezing, thwing, drying and cooking on carotene retention in carrots, broccoli and spinach. Journal of Food Science, London, v.52, n.4, p.1022, 1987.
POLIAKOFF, M.; KING, P. Phenomenal fluids. Nature, London, v.412, p.125, 2001.

RAVENTÓS, M.; DUARTE, S.; ALARCÓN, R. Application and possibilites of supercritical $\mathrm{CO}_{2}$ extraction in food processing industry: na overview.

Food Science and Technology International, Amsterdam, v.8, p.269-284, 2002.

RODRIGUEZ-AMAYA, D.B. Nature and distribution of carotenoids in foods. In: CHARALAMBOL (Ed.). Shelf life of foods and beverages-chemical biological, phisical and nutritional aspec. Amsterdam: Elsevier Sience, 1993. p.547-558.

RODRIGUEZ-AMAYA, D.B. et al. Carotenoid pigment changes in ripening Momordica charantia fruits. Annals of Botany, Rome, v.40, p.615-624, 1976.

SANDLER, S.I. Peng-Robinson equation of state program for a purê fluid for use. 2.ed. Newark: Wiley, 1987.

SIHVONEN, M.; JARVEPÃ, E.; HIETANIEMI, V.; HOUPALAHTI, R. Advances in supercritical carbon dioxide technologies. Trends in Food Science and Technology, Palo Alto, v.10, p.217-222, 1999.

UNIVERSIDADE ESłTADUAL DE SÃO PAULO. Tabela de composição de alimentos:projeto integrado de composição de alimentos. 2001. Disponível em: <http:// www.fcf,usp.br/tabela/resultadò. Acesso em: 10 out. 2007.

USDA. Nutrient database for standard reference, release 14. Washington, 2001. Disponível em: <http:// Wwww.unifesp.br/dis/servcos/nutri/nutri.php? Acesso em: 10 out. 2007. 